\title{
Assessment of the Resilience of a Tartary Buckwheat (Fagopyrum tataricum) Cultivation System in Meigu, Southwest China
}

\author{
Yingjie Song ${ }^{1} \mathbb{D}$, Devra I. Jarvis ${ }^{2,3} \mathbb{(}$, Keyu Bai ${ }^{4,5}$, Jinchao Feng ${ }^{1, *}$ and Chunlin Long ${ }^{1,6, *(\mathbb{D}}$ \\ 1 College of Life and Environmental Sciences, Minzu University of China, Beijing 100081, China; \\ yjsong0517@163.com \\ 2 Platform for Agrobiodiversity Research, c/o Alliance of Bioversity International and CIAT, Maccarese, \\ 00054 Rome, Italy; d.jarvis@cgiar.org \\ 3 Crop and Soil Sciences Department, Washington State University, Pullman, WA 99164, USA \\ 4 Institute of Agricultural Resources and Regional Planning, Chinese Academy of Agricultural Sciences, \\ Beijing 100081, China; k.bai@cgiar.org \\ 5 China Office-Alliance of Bioversity International and CIAT, c/o CAAS, Room 611, Old Building, \\ No. 12 Zhongguancun Nandajie South Street, Beijing 100081, China \\ 6 Kunming Institute of Botany, Chinese Academy of Sciences, Kunming 650201, China \\ * Correspondence: fengjinchao@muc.edu.cn (J.F.); long.chunlin@muc.edu.cn (C.L.)
}

Received: 12 May 2020; Accepted: 10 July 2020; Published: 15 July 2020

\begin{abstract}
Recent socioeconomic development, increased transport and new agricultural technology are endangering the survival of traditional agriculture and the Yi people's traditional knowledge of cultivating Tartary buckwheat. The cultural heritage of Tartary buckwheat cultivation among the Yi communities needs to be investigated and protected before its loss. The main objectives of this study are to document the Tartary buckwheat cultivation system, to analyze the agroecosystem networks that support the current system, and to measure the resilience of the ecological, agricultural and social systems using relevant indicators. The Tartary buckwheat cultivation system in Meigu County uses a rotation system, in which various crops are planted alternatively (e.g., Tartary buckwheat, green manure and potato/corn), utilizing bunch planting and furrow drilling technology. Tartary buckwheat has an important position in the major festival activities among the Yi people's communities. Network analysis on the current agricultural system, ecosystem and social system indicated that the system was stable. The mean score of ecological, agricultural and social stability were 2.50, 2.85 and 2.53, respectively, indicating moderately stability. In contrast, socio-ecological production landscapes and seascapes (SEPLS) resilience indicators in Meigu performed only moderately, with a score of 2.63. The assessment of the resilience of the Tartary buckwheat cultivation system can provide some guidance for policy makers to strengthen biodiversity conservation, sustainable agricultural production and livelihood development (e.g., land use, responding to extreme environmental stresses and improving education levels).
\end{abstract}

Keywords: resilience; Tartary buckwheat; socio-ecological production landscapes and seascapes (SEPLS); Yi ethnic group

\section{Introduction}

Agroecosystems are ecosystems in which people have deliberately selected crop plants and livestock animals to replace the natural flora and fauna [1]. Some agroecosystems are highly simplified, such as the intensive monocropping of crop and orchard species, and intensive livestock rearing. Others are more complex (e.g., varietal mixtures, polycultures, mixed crop-pasture farming and 
agroforestry systems), supporting high levels of biodiversity [1,2]. Agroecosystems cover more than one-quarter of the global land area, reaching about 5 billion hectares [3,4]. Farmers benefit from agroecosystems and the surrounding natural vegetation by harvesting plants for food, medicine and fuel, hunting wild animals, and providing management practices that support the retention of soil and soil fertility, and conserve water [1,3].

Tartary buckwheat (Fagopyrum tataricum (L.) Gaertn.) is an important, highly nutritional and nonpoaceous crop that has great potential as a source of food, forage and medicine [5]. Although it is a minor crop based on global distribution, it is a primary staple food for several sociolinguistic groups in the Himalayas, including Yi, Tibetans and the Bhutanese [6,7]. Liangshan Yi Autonomous Prefecture is the largest Yi people's community in China, located in the center of the origin point of cultivated Tartary buckwheat [8]. It is believed to be the earliest domestication area of Tartary buckwheat [9]. The fossil pollen evidence suggests that Tartary buckwheat was a part of Yi people's diets over a thousand years $[9,10]$. They have formed a unique Tartary buckwheat cultivation system with traditional production methods, rich biodiversity, knowledge systems, cultural diversity and a unique agricultural landscape.

Resilience refers to the capacity or ability to deal with disturbances or changes without altering the essential characteristics of the system [11]. Agroecosystems' resilience does not necessarily mean that the system will return to its original state [12,13]. Instead, a resilient system can absorb disturbances and reorganize while changing to retain essentially the same function and structure [14-16]. There are three central features of resilience: (1) the ability of a system to absorb or buffer disturbances and still maintain its core attributes; (2) the ability of the system to self-organize; and (3) the capacity for learning and adaptation in the context of change [17]. Resilience theory provides a framework to better understand the complex and unpredictable nature of environmental and socio-economic systems. This approach could contribute to maintaining the productivity, health and longevity of these systems [18].

Social-ecological systems can be defined as linked systems between people and nature in which people depend on nature, and nature is influenced by people $[17,19]$. There are a variety of social-ecological systems, such as social-ecological landscapes (socio-ecological production landscapes and seascapes: SEPLS) that link cultural and biological diversity and also represent productive landscapes that people have developed, shaped and maintained sustainably over a long time [20]. SEPLS improve continually, depending on their exposure to disturbances, their resilience, their adaptive cycles and their adaptive capacity in the long-term [21]. The resilience of SEPLS concerns how a society deals with change, and how the capacity for renewal and innovation is provided [17].

The sustainability of the Tartary buckwheat cultivation system in Liangshan Yi Autonomous Prefecture is facing a challenge, due to the popularization and application of modern agricultural technologies, and the impact of mainstream Chinese urban culture. Moreover, more and more younger people are looking for jobs in urban areas. The Tartary buckwheat system is a traditional low-input agroecosystem $[22,23]$. The system's resilience can be increased simply by selecting crop varieties whose traits match certain low-input requirements [24]. As agricultural systems shape the precious assets which they rely on for inputs, a vital feedback loop occurs from outcomes to inputs [23].

In an earlier study, we analyzed the seed flow network for conserving Tartary buckwheat landraces in Lianshan, Southwest China [25]. Our team also used SEPLS indicators to analyze the resilience of Yanuo village, Xishuangbanna, Southwest China. The results revealed that agricultural biodiversity, traditional knowledge and innovation were the primary concerns of the local people in Yanuo Village [26]. How can Tartary buckwheat provide more agroecosystem services expected by farmers? The present study provides an assessment of the resilience of SEPLS in the Tartary buckwheat cultivation system in Meigu County. We aimed to demonstrate that assessing resilience based on the functional traits of the Tartary buckwheat cultivation system in Meigu, dominated by Yi ethnic people, can provide investors and policymakers with ideas to strengthen biodiversity conservation, while improving sustainable agricultural production and livelihood development. 


\section{Materials and Methods}

\subsection{Study Sites}

Liangshan Yi Autonomous Prefecture is the largest community of Yi people in China, located in the southwest of Sichuan Province. Meigu County is in the northeast of Liangshan Yi Autonomous Prefecture, located at $28^{\circ} 01^{\prime}-28^{\circ} 50^{\prime}$ and $102^{\circ} 52^{\prime}-103^{\circ} 20^{\prime}$ (Figure 1). The county profile is long and narrow, extending $46.4 \mathrm{~km}$ from east to west and $94.8 \mathrm{~km}$ from north to south, with a total area of $2573 \mathrm{~km}^{2}$. The highest elevation in Meigu is $4042 \mathrm{~m}$, and the lowest point is only $640 \mathrm{~m}$. It is a low-latitude plateau with a subtropical climate. The geographical environment is complex and diverse; under the influence of the monsoon circulation, unique climate characteristics are formed. The winter and spring are dry, with low temperatures and sufficient sunshine. Summer and autumn are rainy, with high temperatures. The annual average rainfall and temperatures are $814 \mathrm{~mm}$ and $11.4{ }^{\circ} \mathrm{C}$, respectively.

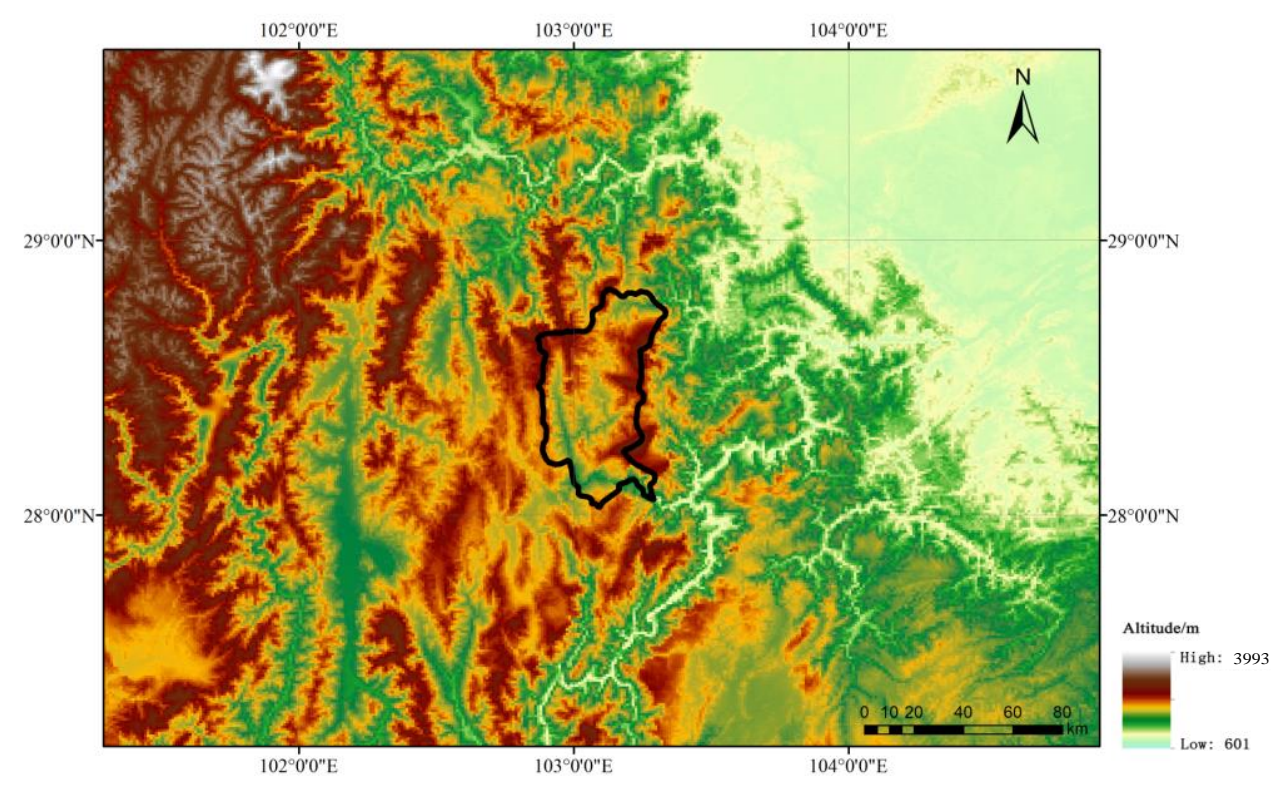

Figure 1. Location of Meigu County.

Meigu County is rich in natural resources, with $324 \mathrm{~km}^{2}$ farming lands, $1085 \mathrm{~km}^{2}$ grassland areas and $1168 \mathrm{~km}^{2}$ forested areas. There are various mineral resources. The main mineral deposits are copper, iron, rare metals, phosphorus, manganese, coal, bauxite, basalt and crystal. Water resources are also plentiful, including plant and animal resources. More than 30 rare and endangered tree species are found in the county, such as Davidia involucrata, Cercidiphyllum japonicum, Tetracentron sinense, and Ginkgo biloba. The sparsely populated land and non-modernized farming techniques allow for a widespread rotation farming system. The nature of the agricultural land has the same characteristics as the soil properties of the natural area, but there is an absolute difference in the material content of the cultivated soils.

\subsection{Method of the Study}

Field investigations were conducted from May to August 2018. In the study area, a total of 77 respondents (Table 1) coming from 17 villages were interviewed, using the approaches of key informant interviews and semi-structured interviews [27]. These 77 respondents ( 44 female and 33 male) were aged from 10 to 98 . A high rate of illiteracy was recorded, with $67.5 \%$ of respondents lacking formal education, and $18.2 \%$ having received only primary school education. In total, $22 \%$ of respondents had migrant work experience. Respondents were asked to introduce the Tartary buckwheat cultivation system in the field. 
Table 1. Population profile of the respondents in the 17 villages.

\begin{tabular}{cccc}
\hline Category of Population Profile & $\begin{array}{c}\text { Characteristics of the } \\
\text { Population Profile }\end{array}$ & $\begin{array}{c}\text { Number of } \\
\text { Respondents }\end{array}$ & $\begin{array}{c}\text { Percentage of } \\
\text { Respondents (\%) }\end{array}$ \\
\hline Gender & Male & 33 & 42.9 \\
Age range & Female & 44 & 57.1 \\
& $10-29$ & 14 & 18.2 \\
& $30-39$ & 15 & 19.5 \\
Education level & $40-49$ & 22 & 28.5 \\
& $50-59$ & 12 & 15.6 \\
& $60-90$ & 14 & 18.2 \\
& Illiterate & 52 & 67.5 \\
& Primary school & 14 & 18.2 \\
& Middle school & 7 & 9.0 \\
& High school & 3 & 3.9 \\
Outing experience & University & 1 & 1.3 \\
& No outing experience & 60 & 77.9 \\
& Migrant working & 17 & 22.1 \\
\hline
\end{tabular}

The fifteen indicators of resilience in SEPLS were designed to capture local people's perceptions of the resilience of Tartary buckwheat cultivation system. All of the indicators cover three aspects: the ecosystem, agricultural system and social systems (Table 2). At the beginning of the participatory research, the assessment methodology and indicators were introduced to all of the respondents. All respondents were asked to give a score for fifteen indicators for the SEPLS. The specific approach was to evaluate a score for all indicators, with 1-5 points. Then, the scores for the all indicators were collected. Average scores for each category were then calculated. According to the preferences which the respondents expressed, the most suitable choices in the 1-5 point scale were ranked from the lowest to the highest degree (e.g., 1: deficient degree of resilience, 3: moderate degree of resilience and 5: very high degree of resilience) [12]. In other words, a score of 1 means that the landscape or seascape performs very poorly, and a score of 5 means an extremely good performance.

Table 2. The resilience assessment indicators for the SEPLS.

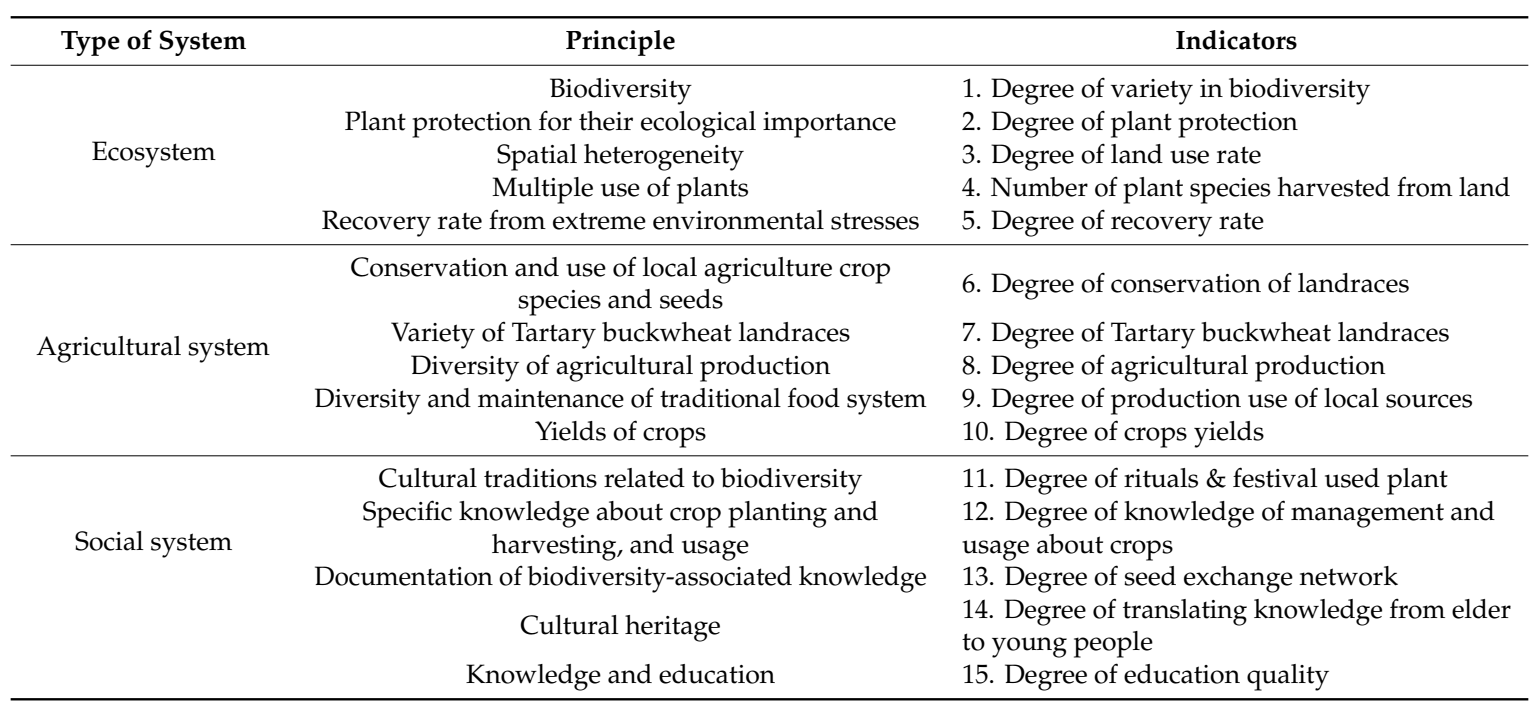

To assess the system's stability, network mapping of the indicators was performed using UciNet, version 6.21 [28]. These analyses resulted in three main measures of network centrality. One of these measures was chosen to evaluate the stability of the system; namely, degree centrality. The degree centrality of an indicator measures its level of direct connectedness to other indicators; a higher number indicates better connectivity. The density of the network was also calculated with $\mathrm{D}=m /\left(\frac{n(n-1)}{2}\right)$ 
(D: density of network; $m$ : number of actual relationships; $n$ : number of indicators). A modularization analysis was also conducted to help understand the structure and function of the network.

\subsection{Data Analysis}

The collected data were analyzed using SPSS, version 20.0 (SPSS Inc., Chicago, IL, USA). The average value of ecological, agricultural, and social resilience was calculated by dividing the total amount attached to the system by the total number of respondents. The mean value of three types of systems was used to assess the overall resilience of the SEPLS. It was used to evaluate the resilience of the Tartary buckwheat cultivation system in Meigu County.

\section{Results}

\subsection{Definition of the System}

To illustrate the characteristics of the Tartary buckwheat cultivation system (Figure 2) in Meigu County, the structure and function of this cultivation system was analyzed. The system is rain-fed agriculture with low inputs. Figure 3 shows a structured flowchart of the system. External contributions to the system include crop seeds, livestock breeds, inorganic fertilizer and traditional management. Tartary buckwheat, oat, corn, Brassica rapa L., Phaseolus vulgaris L. and soya bean are the main crops in this system. Tartary buckwheat and other crops co-occupy the time and space of growth, forming a network of complementary biodiversity. The livestock in the system is also diverse, including cattle, sheep, goats, pigs and chicken. The integrated model with crops and animal husbandry is a characteristic feature of the system. Tartary buckwheat's by-products are used to feed livestock as high-quality fodder, and the livestock manure is used as high-quality organic fertilizer. Management is another vital input in this system. The system uses a rotation system (green manure, Tartary buckwheat, green manure, potato/corn), in which various crops are planted in rotation, using bunch planting and furrow drilling technology. Different Tartary buckwheat landraces were selected and cultivated in different habitats and planted on different dates. Rituals are also part of the cultivation, and specific rituals must be held before sowing and before harvesting.

The Tartary buckwheat cultivation system's functions are mainly reflected through ecosystem services. The system provides massive amounts of food, raw materials and energy for local $\mathrm{Yi}$ people. Tartary buckwheat is one of the staple foods within the system. Various crops are cultivated in alternation (e.g., Tartary buckwheat, green manure, potato/corn), which ensures agricultural biodiversity and helps to improve soil, while controlling soil erosion. Furthermore, the system is also part of the cultural heritage of the Yi People.

\subsection{Agroecosystem Network Structure}

To understand how the Tartary buckwheat cultivation system might change in response to environmental stress, the agroecosystem will now be introduced from the standpoint of network approaches (Figure 3). For instance, we explored how concepts such as modularity, nestedness, and connectance might impact the stability of the interaction networks [29-31] and, consequently, how these might impact the ecosystem's emergent functions [32]. Table 3 shows the characteristics of the indicators that were active in the agroecosystem network, and their degree centrality. It also shows the indicators' position in the network. Furthermore, the density of network was 1.40. Based on the analysis of the network and its centrality, the network map was generated through UciNet. The significant levels of modularity exhibited by all 15 indictors of the three systems networks in our study (Figure 4) have important implications for the management of Tartary buckwheat landraces, the conservation of biodiversity in agricultural landscapes, and the heritage of traditional culture and knowledge. For example, a farm disturbance effect illustrates how changes in the conventional food system are connected to changes in biodiversity levels, spatial heterogeneity, the conservation and use 
of local agriculture crop species, Tartary buckwheat landrace diversity, agricultural production directly, and the loss of knowledge and culture about crops and plants.
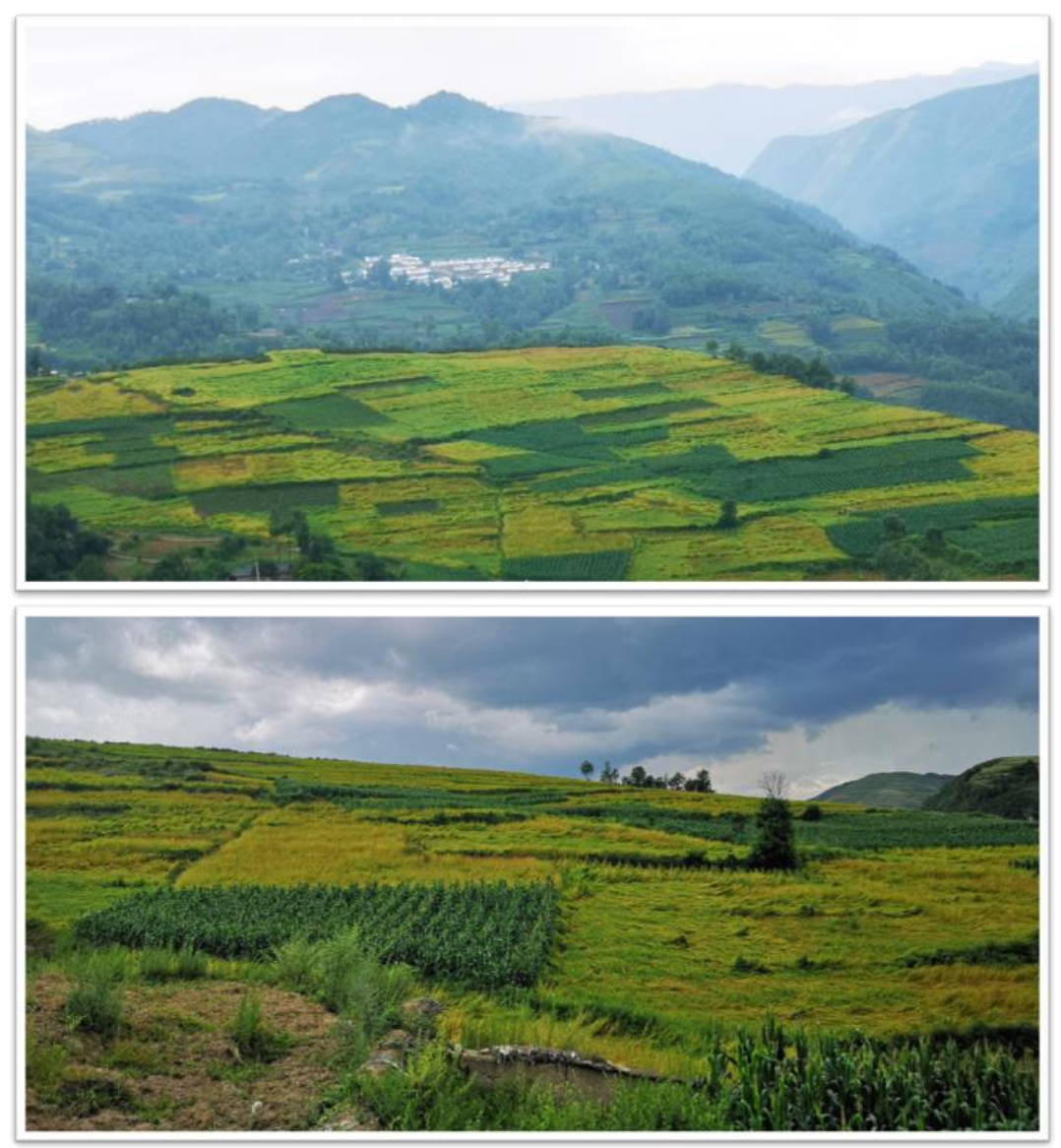

Figure 2. Tartary buckwheat (Fagopyrum tataricum) cultivation system in Meigu. (Upper part shows the whole Tartary buckwheat cultivation system, including village and farmland; lower part shows Tartary buckwheat, corn and potato in farmland).

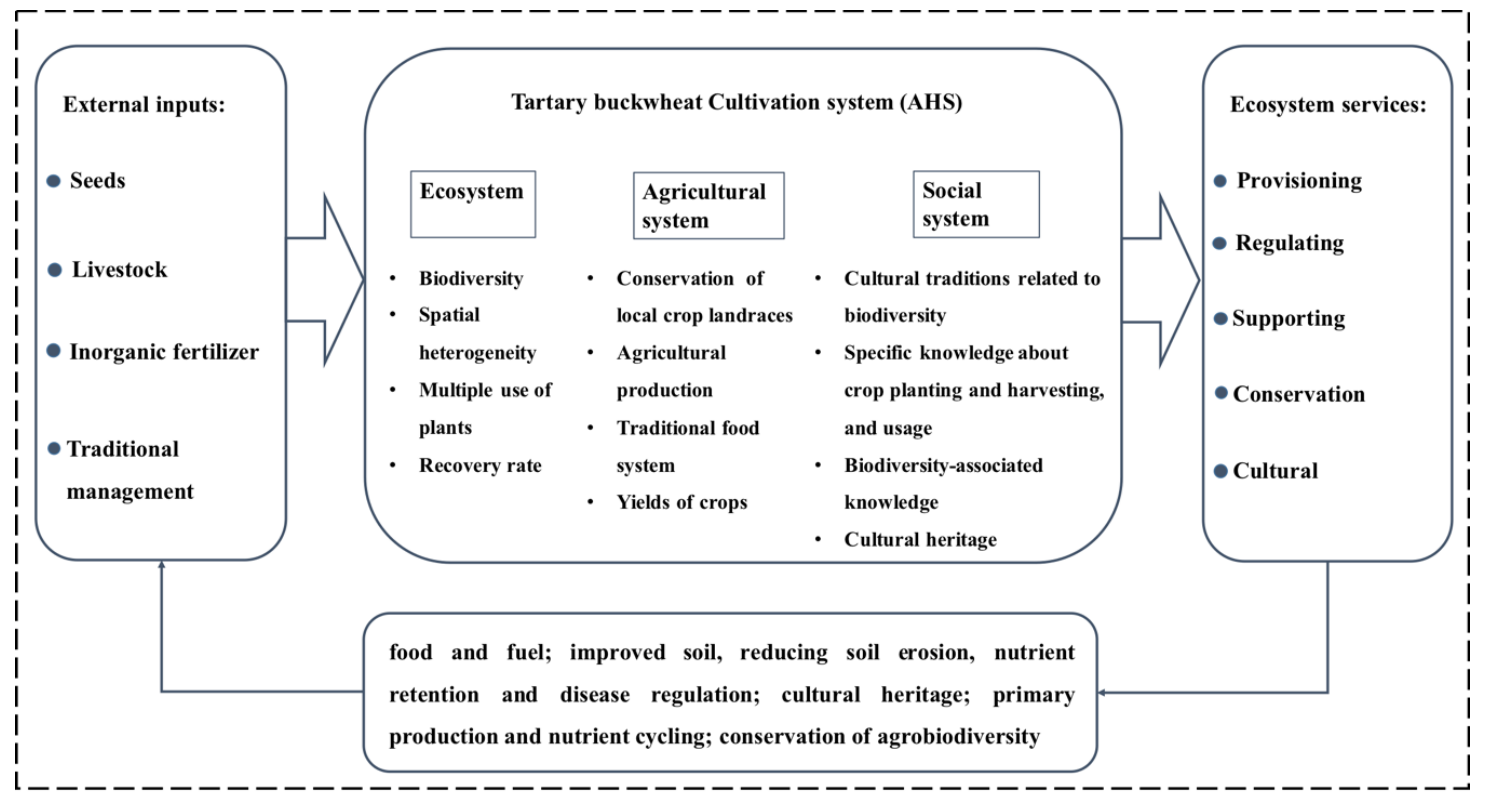

Figure 3. Structure flowchart of the Tartary buckwheat cultivation system. 
Table 3. Characterization of indicators in the agroecosystem network.

\begin{tabular}{cc}
\hline Indicators & Degree Centrality \\
\hline Degree of variety in biodiversity & 14.39 \\
Degree of plant protection & 12.70 \\
Degree of land use rate & 12.70 \\
Number of plant species harvested from land & 11.85 \\
Degree of recovery rate & 8.47 \\
Degree of conservation of landraces & 14.39 \\
Degree of Tartary buckwheat landraces & 11.00 \\
Degree of agricultural production & 11.00 \\
Degree of production use of local sources & 13.55 \\
Degree of crops yields & 11.00 \\
Degree of rituals \& festival used plant & 11.00 \\
Degree of seed exchange network & 13.55 \\
Degree of knowledge of management and usage about crops & 11.00 \\
Degree of translating knowledge from elder to young people & 11.00 \\
Degree of education quality & 8.47 \\
Density & 1.40 \\
\hline
\end{tabular}

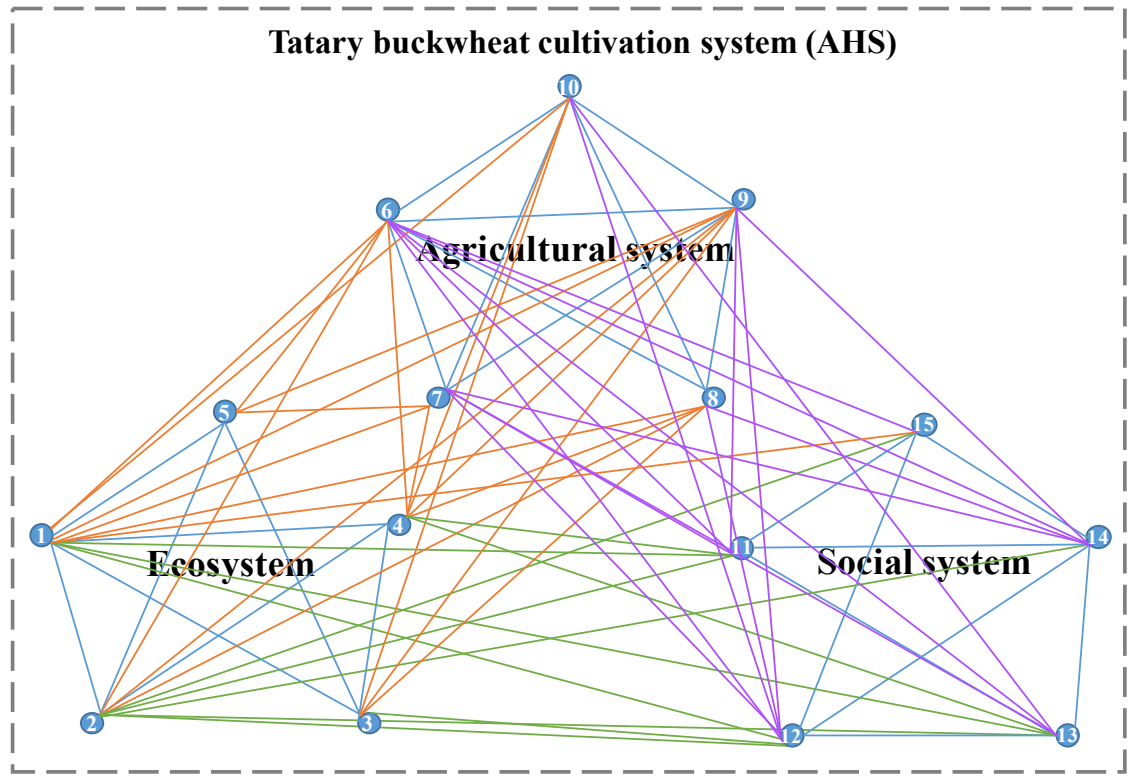

Each node represents a indicator of the Tartary buckwheat cultivation system and a line between two nodes indicates those two indicators interact in some way.

Figure 4. The network of the Tartary buckwheat cultivation system. (1: Degree of variety in biodiversity; 2: Degree of plant protection; 3: Degree of land use rate; 4: Number of plant species harvested from land; 5: Degree of recovery rate; 6: Degree of conservation of landraces; 7: Degree of Tartary buckwheat landraces; 8: Degree of agricultural production; 9: Degree of production use of local sources; 10: Degree of crops yields; 11: Degree of rituals \& festival used plant; 12: Degree of knowledge of management and usage about crops; 13: Degree of seed exchange network; 14: Degree of translating knowledge from elder to young people; 15: Degree of education quality). 
3.3. The Resilience of the Socio-Ecological Production Landscapes and Seascapes (SEPLS) in the Tartary Buckwheat Cultivation System in Meigu County

\subsubsection{The Ecological Resilience of SEPLS}

The ecological resilience of the SEPLS in the Tartary buckwheat cultivation in Meigu County refers to the conservation and maintenance of biodiversity. Table 4 shows that the degree of variety in biodiversity, plant conservation, land use rate, plant species harvested from the land and the recovery rate are $2.91 \pm 0.73,3.04 \pm 0.79,1.84 \pm 0.67,3.01 \pm 0.72$ and $1.71 \pm 0.65$, respectively. The average value of ecological resilience is at a moderate level, with a magnitude of 2.50 .

Table 4. Measuring the resilience of SEPLS.

\begin{tabular}{ccc}
\hline Type of System & Indicators & Mean Score (1-5 Point) \\
\hline \multirow{3}{*}{ Ecosystem } & Degree of variety in biodiversity & $2.91 \pm 0.73$ \\
& Degree of plant protection & $3.04 \pm 0.79$ \\
& Degree of land use rate & $1.84 \pm 0.67$ \\
& Number of plant species harvested from land & $3.01 \pm 0.72$ \\
Agricultural system & Degree of recovery rate & $1.71 \pm 0.65$ \\
\hline & Degree of conservation of landraces & $2.69 \pm 0.99$ \\
& Degree of Tartary buckwheat landraces & $3.13 \pm 0.97$ \\
& Degree of agricultural production & $2.90 \pm 0.75$ \\
& Degree of production use of local sources & $2.78 \pm 0.82$ \\
& Degree of crops yields & $2.73 \pm 0.88$ \\
\hline \multirow{2}{*}{ Social system } & Degree of knowledge of management and usage about crops & $2.77 \pm 0.93$ \\
& Degree of seed exchange network & $2.94 \pm 0.78$ \\
& Degree of translating knowledge from elder to young people & $3.05 \pm 0.79$ \\
& Degree of education quality & $2.34 \pm 0.74$ \\
& & $1.57 \pm 0.85$ \\
\hline
\end{tabular}

\subsubsection{The Agricultural Resilience of SEPLS}

The resilience of the agricultural system means the conservation and maintenance of agricultural production in the Tartary buckwheat cultivation system in Meigu County. The conservation and use of local agricultural crop species and seeds, varieties of Tartary buckwheat landraces, diversities of agricultural production, diversities and maintenance of the traditional food system, and yields of crops were selected to evaluate the agricultural resilience. The average value of these five indicators were $2.69 \pm 0.99,3.13 \pm 0.97,2.90 \pm 0.75,2.78 \pm 0.82$ and $2.73 \pm 0.88$ (Table 4). The average amount of agricultural resilience was at a moderate level, with a magnitude of 2.85 .

\subsubsection{The Social Resilience of SEPLS}

The resilience of the social system means the sustainable livelihood development in the Tartary buckwheat cultivation system in Meigu County. The cultural traditions related to biodiversity; specific knowledge about crop planting, harvesting and usage; documentation of biodiversity-associated experience; cultural heritage; and education were selected to measure the resilience of the system. Evaluation of the measurement shows that the value of these indicators is $2.77 \pm 0.93,2.94 \pm 0.78$, $3.05 \pm 0.79,2.34 \pm 0.74,1.57 \pm 0.85$, respectively. The average value of social resilience is at a moderate level, with a magnitude of 2.53 .

\subsubsection{The Overall Resilience of SEPLS}

The overall resilience of the SEPLS was assessed to be moderate, with a magnitude of 2.63 . The evaluation of Figure 5 shows that the overall resilience trend of the entire SEPLS system in Meigu County is at a moderate level. The results of this assessment draw attention to the indicators that affect the resilience of the Tartary buckwheat cultivation system. Meanwhile, this assessment also helps 
us to monitor changes and interactions in the system. All of these aim toward the conservation of biodiversity, agricultural production and sustainable livelihood development.

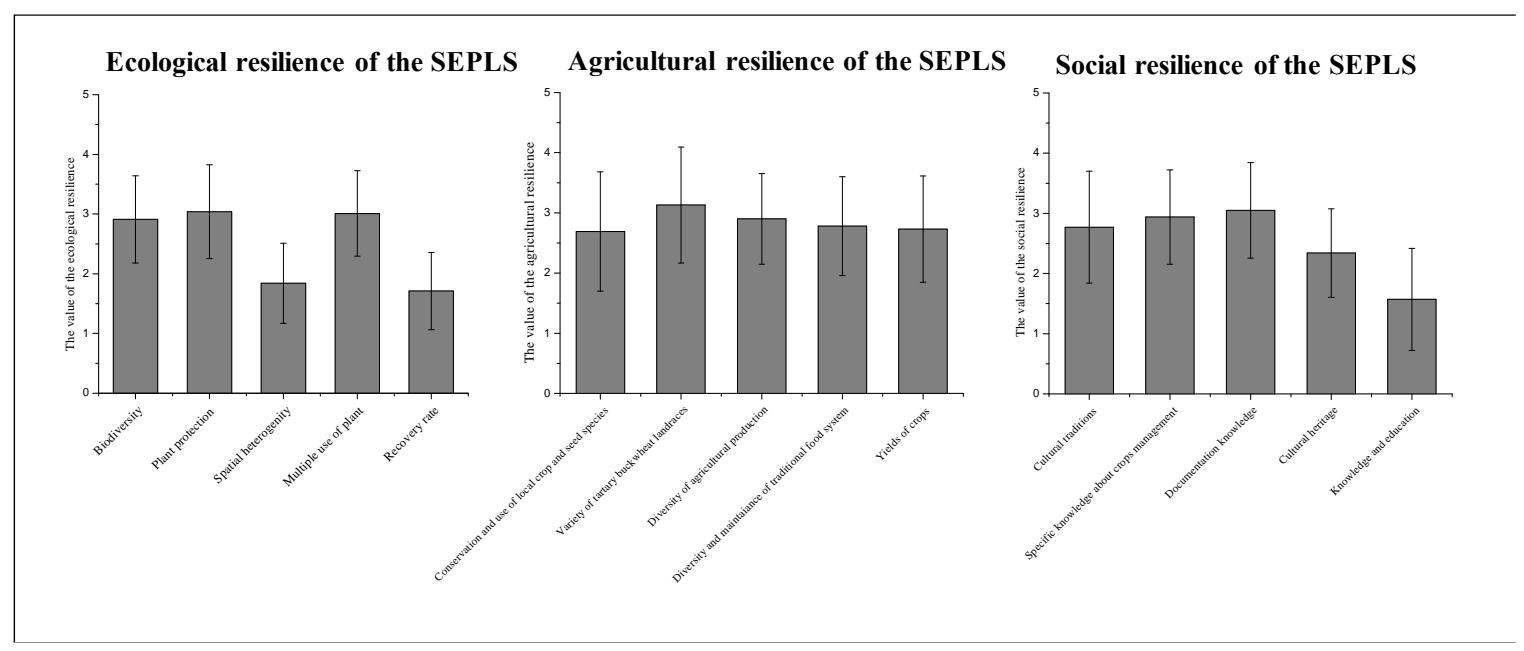

Figure 5. Resilience of SEPLS in the Tartary buckwheat cultivation system in Meigu.

\section{Discussion}

The Tartary buckwheat cultivation system consists of an ecosystem, an agricultural system and a social system. The ecosystem's traits include abundant biodiversity, appropriate spatial heterogeneity and a specific recovery rate in extreme environmental stresses. The agricultural system plays an essential role in the conservation and use of local agriculture crop species and seeds, the diversity of agricultural production, and maintenance of the traditional food system [33]. Furthermore, local farmers have accumulated rich experience in adapting to nature, including cultural traditions related to biodiversity management and use, specific knowledge about crop planting and harvesting, plant usage for health and cultural activities.

In the study area, the land use rate is reducing due to labor migration. More and more younger people are looking for jobs in urban areas, which leads to more and more land being left uncultivated. Moreover, the recovery rate from extreme environmental stresses is at a low level due to difficult local ecological conditions. For example, once hailstones pelt crops, farmers lose production and may not have resources to plant the next season. The plant species in the Tartary buckwheat cultivation system are diverse, including crops, vegetables, wild edible plants and medicinal plants, which provide an alternative income if the main crop is lost. Even so, the land use and recovery rates are low after environmental damage events. Farmers keep five or six crops cultivated, with several Tartary buckwheat landraces. For example, there were at least two Tartary buckwheat landraces in each household. Unfortunately, there are few policies on the conservation of crop landraces. With abundant crop resources, the degree of the diversity of agricultural production was at a moderate level. The diversities and maintenance of traditional food systems has also decreased because of the influence of foreign food culture. Furthermore, Yi people have kept diverse traditional cultures related to crops, wild plants and livestock. Farmers, especially elders, master specific knowledge about crop planting, harvesting, management and usage. They also pass on this knowledge to the next generation as much as possible. However, the transmission and documentation of this knowledge was shown to be far from sufficient for the sustainability of this knowledge base. With the development of modern agriculture and the influence of foreign culture, more and more young people have lost interest in learning traditional knowledge and culture. The evaluation of knowledge and education levels showed that the degree of education quality was low in the study area, and has affected local peoples' cognition of landrace conservation, biodiversity, land use and some special usages (Figure 4). 
The ecosystem services of the Tartary buckwheat cultivation system include provisioning, supporting, regulating and cultural services. Farmland is managed for crop and livestock production, which provides food for farmers, such as the staple foods of Tartary buckwheat, potato and corn, as well as livestock meat. In addition, fiber fuel is provided, including plant straw and tree branches. Despite a recent surge in research in ecosystem services management, research in crop production systems are still missing [34]. There are also significant negative impacts on the environment and biodiversity that are becoming evident $[35,36]$, some of which might even have negative feedbacks on sustained crop productivity [37]. Therefore, provisioning food and fuel for farmers is essential in the system. More than one-fifth of the global soil carbon pool is stored in agricultural soil [38]. This system provides water storage and purification, carbon storage and gas regulation, and a reduction in air pollution. Lastly, it also has the function of cultural inheritance. The birth, full moon, adult etiquette, marriage, funeral, ancestral ceremony, family vows, walking out, marching, working and hunting of Yi people are inseparable from Tartary buckwheat. Tartary buckwheat cultivation and dietary culture play an essential role in the ethnic identity of the Yi people. The identification and development of Yi people's social organization enhance national spirit and belief, and it has significant cultural awareness and research value.

Earlier studies have analyzed and discussed the importance of the traditional cultures and knowledges of China to the conservation of biodiversity [39]. Diversity has been positively linked to the stability of systems [40-42]. When facing disturbances, traditional food systems are challenging to change, due to the many factors that sustain their integrity. From the network map (Figure 4), we conclude that the integrity of the system is high. These assessment results draw attention to the indicators that affect the resilience of the Tartary buckwheat cultivation system.

\section{Conclusions}

The results show that the Tartary buckwheat cultivation system in Meigu County is an integrated model with crop growing and animal husbandry. The system inherits the traditional knowledge of agricultural management and culinary folk culture. It is, therefore, of considerable significance to the protection of ecological security and to ensure food security. Through network structure analysis, we conclude that the system maintains high integrity and stability. At the same time, measured resilience values can provide significant guidance to policy makers to strengthen biodiversity conservation, concurrently supporting the improvement of sustainable agricultural production and livelihood development. These measurements of local resilience need to be integrated into policy decisions, including a greater emphasis paid to land use and ecosystem recovery rates and local education. Socioecological resilience assessment is also a key for monitoring the changes and interactions of the components in diverse agricultural ecosystems to support the conservation of biodiversity, agricultural production and sustainable livelihood development.

Author Contributions: C.L. and J.F. conceived this study. Y.S. carried out the field investigations, analyzed and interpreted the data, and drafted the manuscript. D.I.J. and K.B. gave inputs to the study design, edited the English and provided useful comments. C.L. finalized the manuscript. All authors read and approved the final manuscript.

Funding: This research was funded by the National Natural Science Foundation of China [31761143001, 31870316], the Ministry of Ecological Environment of China (2019HB2096001006), the Key Laboratory of Ethnomedicine (Minzu University of China) of the Ministry of Education of China [KLEM-ZZ201806, KLEM-ZZ201906], Minzu University of China [Collaborative Innovation Center for Ethnic Minority Development and yldxxk201819], and the Ministry of Education of China and State Administration of Foreign Experts Affairs of China [B08044].

Acknowledgments: We are very grateful to the Yi people, who provided valuable information, traditional knowledge and culture about Tartary buckwheat.

Conflicts of Interest: The authors declare no conflict of interest. 


\section{References}

1. Altieri, M.A.; Koohafkan, P. Globally important ingenious agricultural heritage systems (GIAHS): Extent, significance, and implications for development. In Proceedings of the Second International Workshop and Committee Meeting for the Globally Important Agricultural Heritage Systems (GIAHS) Project, Buenos Aires, Argentina, 21-23 October 2009; FAO: Rome, Italy. Available online: http://www.fao.org/3/ap021e/ap021e.pdf (accessed on 15 December 2019).

2. Moguel, P.; Toledo, V.M. Biodiversity conservation in traditional coffee system of Mexico. Conserv. Biol. 1999, 13, 11-21. [CrossRef]

3. Vandermeer, J. Tropical Agroecosystems; CRC Press: Boca Raton, FL, USA, 2003; p. 194.

4. Estrada, A.; Raboy, B.; Oliveira, L.C. Agroecosystems and primate conservation in the tropics: A review. Am. J. Primatol. 2012, 1-16. [CrossRef]

5. Holasova, M.; Fiedlerova, V.; Smrcinova, H.; Orsak, M.; Lamchman, J.; Vavreinova, S. Buckwheat-the source of antioxidant activity in function foods. Food Res. Int. 2002, 35, 207-211. [CrossRef]

6. Bisht, I.S.; Mehta, P.S.; Bhandari, D.C. Traditional crop diversity and its conservation on-farm for sustainable agricultural production in Kumaon Himalaya of Uttaranchal state: A case study. Genet. Resour. Crop Evol. 2007, 54, 345-357. [CrossRef]

7. Huang, W.J.; Jarvis, D.I.; Ahmed, S.; Long, C.L. Tartary buckwheat genetic diversity in the Himalayas associated with farmer landrace diversity and low dietary dependence. Sustainability 2017, 9, 1806. [CrossRef]

8. Ohnishi, O. Discovery of new Fagopyrum species and its implication for the studies of evolution of Fagopyrum and of the origin of cultivated buckwheat. In Current Advances in Buckwheat Research; Matano, T., Ujihara, A., Eds.; Shinshu University Press: Nagano, Japan, 2016; Volume I-III, pp. 175-190.

9. Jones, M.K.; Liu, X.Y. Origins of agriculture in East Asia. Science 2009, 324, 730. [CrossRef] [PubMed]

10. Jarvis, D.I. Pollen evidence of changing Holocene monsoon climate in Sichuan Province, China. Quat. Res. 1993, 39, 325-337. [CrossRef]

11. Plieninger, T.; Bieling, C. Connecting cultural landscapes to resilience. In Resilience and the Cultural Landscape: Understanding Change in Human-shaped Environments; Plieninger, T., Bieling, C., Eds.; Cambridge University Press: Cambridge, UK, 2012; pp. 3-26.

12. Ciftcioglu, G.C. Assessment of the resilience of socio-ecological production landscapes and seascapes: A case study from Lefke Region of North Cyprus. Ecol. Indic. 2017, 73, 128-138. [CrossRef]

13. Cabell, J.F.; Oelofse, M. An indicator framework for assessing agroecosystem resilience. Ecol. Soc. 2012, 17, 18. [CrossRef]

14. Walker, B.; Meyers, J.A. Thresholds in ecological and social? ecological systems: A developing database. Ecol. Soc. 2004, 9, 3. [CrossRef]

15. Unnasch, R.S.; Braun, D.P.; Comer, P.J.; Eckert, G.E. The Ecological Integrity Assessment Framework: A Framework for Assessing the Ecological Integrity of Biological and Ecological Resources of the National Park System Report to the National Park Service. 2018. Available online: https://www.natureserve.org/fr/node/161 (accessed on 16 December 2019).

16. UNU-IAS United Nations University Institute of Advanced Studies. Indicators of resilience in socio-ecological landscapes (SEPLs). UNU-IAS Policy Report (Authors: Bergamini, N.; Blasiak, R.; Eyzaguirre; Ichikawa, K.; Mijatovic, D.; Nakao, F.; Subramanian, S.M.). 2013. Available online: http://archive.ias.unu.edu/resource. centre/Indicators-of-resilience-in-sepls.ev.pdf (accessed on 11 November 2019).

17. Berkes, F.; Colding, J.; Folke, C. (Eds.) Navigating Social-Ecological Systems: Building Resilience for Complexity and Change; Cambridge University Press: New York, NY, USA, 2003.

18. Wheatbelt, NRM Inc. Natural resource management incorporated 2013 resilience. Strateg. Rev. 2013. Available online: http://www.wheatbeltnrm.org.au/ (accessed on 15 October 2019).

19. Matthews, R. The people and landscape model (PALM): Towards full integration of human decision-making and biophysical simulation models. Ecol. Model. 2006, 194, 329-343. [CrossRef]

20. Gallopiín, G.C. Linkages between vulnerability, resilience, and adaptive capacity. Global Environ. Chang. 2006, 16, 293-303. [CrossRef]

21. Charette-Castonguay, A. Assessment of Resilience and Adaptability of Social-Ecological Systems: A Case Study of the Banaue Rice Terraces. Master's Thesis, Institute for Natural Resource Conservation, Kiel University, Kiel, Germany, 2014. 
22. Ratnadass, A.; Fernandes, P.; Avelino, J.; Habib, R. Plant species diversity for sustainable management of crop pests and diseases in agroecosystems: A review. Agron. Sustain. Dev. 2012, 32, 273-303. [CrossRef]

23. Pretty, J.; Bharcha, Z.P. Sustainable intensification in agricultural systems. Ann. Bot. 2014, 114, 1571-1596. [CrossRef]

24. Jackson, W. Natural systems agriculture: A truly radical alternative. Agr. Ecosyst. Environ. 2002, 88, 111-117. [CrossRef]

25. Song, Y.; Fang, Q.; Jarvis, D.I.; Bai, K.; Liu, D.; Feng, J.; Long, C.L. Network analysis of seed flow, a traditional method for conserving Tartary buckwheat (Fagopyrum tataricum) landraces in Liangshan, Southwest China. Sustainability 2019, 11, 4263. [CrossRef]

26. Yang, Y.; Bai, K.; Li, G.; Jarvis, D.; Long, C.L. Assessment of the resilience in SEPLS (Social- Ecological Production Landscapes and Seascapes) in Yanuo Village, Xishuangbanna, Southwest China. Sustainability 2020, 12, 3774. [CrossRef]

27. Alexiades, M.N.; Sheldon, J.W. Selected Guidelines for Ethnobotanical Research: A Field Manual; New York Botanical Garden: New York, NY, USA, 1996.

28. Borgatti, S.; Everett, M.; Freeman, L. UciNet Visualization; Analytic Technologies: Lexington, KY, USA, 2012.

29. Thebault, E.; Fontaine, C. Stability of ecological communities and the architecture of mutualistic and trophic networks. Science 2010, 329, 853-856. [CrossRef] [PubMed]

30. Allesina, S.; Tang, S. Stability criteria for complex ecosystems. Nature 2012, 483, 205-208. [CrossRef]

31. James, A.; Pitchford, J.W.; Plank, M.J. Disentangling nestedness from models of ecological complexity. Nature 2012, 487, 227-230. [CrossRef]

32. Thompson, R.M.; Brose, U.; Dunne, J.A.; Hall, R.O.; Hladyz, S.; Kitching, R.L.; Martinez, N.D.; Rantala, H.; Romanuk, T.N.; Stouffer, D.B.; et al. Food webs: Reconciling the structure and function of biodiversity. Trends Ecol. Evol. 2012, 27, 689-697. [CrossRef] [PubMed]

33. Power, A.G. Ecosystem services and agriculture: Tradeoffs and synergies. Philos. T. R. Soc. B. 2010, 365, 2959-2971. [CrossRef] [PubMed]

34. Kremen, C.; Miles, A.F. Ecosystem services in biologically diversified versus conventional farming systems: Benefits, externalities, and trade-offs. Ecol. Soc. 2012, 17, 40. [CrossRef]

35. Moss, B. Water pollution by agriculture. Philos. T. R. Soc. B. 2008, 363, 659-666. [CrossRef] [PubMed]

36. Potts, S.G.; Biesmeijer, J.C.; Kremen, C.; Nermann, P.; Schweiger, O.; Kunin, W.E. Global pollinator declines: Trends, impacts and drivers. Trends Ecol. Evol. 2010, 25, 345-353. [CrossRef] [PubMed]

37. Matson, P.A. Agricultural intensification and ecosystem properties. Science 1997, 277, 504-509. [CrossRef]

38. Bommarco, R.; Kleijn, D.; Potts, S.G. Ecological intensification: Harnessing ecosystem services for food security. Trends Ecol. Evol. 2013, 28, 230-238. [CrossRef]

39. Pei, S.J. Traditional culture and biodiversity conservation. Bull. Chin. Acad. Sci. 2010, 2, 190-196. (In Chinese)

40. Haddad, N.M.; Crutsinger, G.M.; Gross, K.; Haarstad, J.; Tilman, D. Plant diversity and the stability of foodwebs. Ecol. Lett. 2011, 14, 42-46. [CrossRef]

41. Loreau, M.; Mazancourt, C.D. Biodiversity and ecosystem stability: A synthesis of underlying mechanisms. Ecol. Lett. 2013, 16 (Suppl. 1), 106-115. [CrossRef]

42. Tilman, D.; Reich, P.B.; Knops, J.M. Biodiversity and ecosystem stability in a decade-long grassland experiment. Nature 2006, 441, 629-632. [CrossRef] [PubMed]

(C) 2020 by the authors. Licensee MDPI, Basel, Switzerland. This article is an open access article distributed under the terms and conditions of the Creative Commons Attribution (CC BY) license (http://creativecommons.org/licenses/by/4.0/). 